\title{
"Best of Both Worlds": A Students-as-Partners Near-Peer Moderation Program Improves Student Engagement in a Course Facebook Group
}

\author{
Mohammad Jay ${ }^{a}$, Michelle Lim ${ }^{b}$, Khalid Hossein ${ }^{c}$, Tara Whited ${ }^{d}$, Syed Reza Naqvi ${ }^{b}$, Kevin \\ Chien $^{a}$, and *Tom Haffie ${ }^{\text {b }}$
}

aUniversity of Ottawa, Ottawa, Ontario, Canada

${ }^{b}$ Western University, London, Ontario, Canada

'McGill University, Montreal, Quebec, Canada

dVrije Universiteit, Amsterdam, The Netherlands

Contact: thaffie@uwo.ca

\section{ABSTRACT}

Social media platforms like Facebook are designed to facilitate online communication and networking, primarily around content posted by users. As such, these technologies are being considered as potential enhancements to traditional learning environments. However, various barriers to effective use may arise. Our research investigated the effectiveness of a students-as-partners near-peer moderation project, arising from collaboration between instructors and senior students, as a vehicle for enhancing student interaction in a Facebook group associated with a large introductory science course. The quantity and quality of sample posts and comments from Facebook groups from three successive academic years were evaluated using a rubric that considered characteristics such as civility, content accuracy, critical thinking and psychological support. Two of these groups were moderated by near-peer students while the third group was not moderated. We found improved course discussion associated with moderated groups in addition to benefits to moderators and the faculty partner. This suggests that near-peer moderation programs working in collaboration with faculty may increase student engagement in social media platforms.

\section{KEYWORDS}

social media, facebook, peer support, students-as-partners

Social media platforms (e.g., Facebook, Twitter, Instagram, Myspace, LinkedIn, Snapchat, WeChat) are intended to facilitate personal and/or professional online communication, community building, and networking. Usage of such platforms has 
increased in popularity among university students in recent years, to the point that many typically access them several times daily (Alhabash \& Ma, 2017; McCole, Everett, \& Rivera, 2014). Therefore, it is no surprise that instructors have attempted to leverage social media tools to augment the synchronous, face-to-face, print-based learning environments of typical university courses (Al-Bahrani \& Patel, 2015; Freyn, 2017; Schroeder \& Greenbowe, 2009; Soluk \& Buddle, 2015; Y. Wang, Fang, Han, \& Chen, 2016; Q. Wang, Woo, Quek, Yang, \& Liu, 2012).

Facebook is a particularly pervasive social networking platform that is among the most frequently visited online sites for young adults (Greenwood, Perrin, \& Duggan, 2016). Unofficial Facebook groups are routinely created and administered by students to communicate with each other about their university courses, and formal incorporation of Facebook into learning environments has taken several forms (Irwin, Ball, \& Desbrow, 2012; Manca \& Ranieri, 2015; McCole et al., 2014; Schroeder \& Greenbowe, 2009; Thompson, 2007; Q. Wang et al., 2012). See Chugh and Ruhi (2018) for a recent review.

Many modern science courses have an associated online site created through an institutionally supported Learning Management System (LMS, e.g., Blackboard, Moodle, Brightspace, etc.) that incorporates social media features such as text or video message boards, chatrooms, podcasts, and email. A study by Schroeder and Greenbowe (2009) found that, in an organic chemistry course with both a Facebook group and an LMS site, the Facebook group received almost $400 \%$ more posts than the LMS site. This study highlighted several attractive features of Facebook as an educational technology for students. First, they are notified of recent academic group activity alongside notifications from their personal networks, which they already check quite regularly. Second, questions in the Facebook group received faster and more detailed responses from peers. And finally, students are familiar with the Facebook interface and generally feel it is a judgement-free and less intimidating environment for posing questions than the LMS (Irwin et al., 2012; Schroeder \& Greenbowe, 2009). Facebook has also been promoted as a potential academic communication tool due to the ease of facilitating discussion around shared multimedia such as pictures, videos, and links to other resources (McCole et al., 2014; Schroeder \& Greenbowe, 2009).

However, ease of communication does not ensure positive outcomes of communication. This is particularly relevant if the participants are members of disparate demographic groups, such as is often the case with professors and their students. More widespread adoption of Facebook as an educational technology has been hampered by incompatibilities with established synchronously face-to-face instructional methods, fears that it will undermine the professional relationship between professors and students, privacy concerns for faculty and students, online incivility, eroding academic integrity, and lack of authoritative content oversight (DiVall \& Kirwin, 2012; Irwin et al., 2012; Legaree, 2015; Manca \& Ranieri, 2016; Wang et al., 2012).

Students as Partners is a global initiative that fosters partnerships within which undergraduate students collaborate with professors on projects related to the educational mission of their institution (Bovill, Cook-Sather, Felten, Millard, \& MooreCherry, 2016; Matthews, 2017). With students stepping into roles as consultants, evaluators, co-facilitators, co-instructors, co-designers, or co-researchers, opportunities arise for new kinds of academic relationships to emerge based on synergistic skillsets, 
interdependence, mutual respect, and shared commitment to enriching the educational experience for students and faculty alike (Healey, Flint \& Harrington, 2014; Weller, Domarkaite, Lam, Lam, \& Metta, 2013). One specific example of initiatives that lend themselves quite naturally to a students-as-partners approach is peer-assisted learning programs (Rivers et al., 2017; O'Shea, Bennett, \& Delahunty, 2017).

In the context of our project, students initially contributed as co-designers and principal implementers of academic support programming. They then collaborated as co-researchers and co-authors on this investigation of program effectiveness. Our guiding research question was: Did our near-peer support initiative, called the Biology Mentor Program, improve the quality of student interaction in a course-associated Facebook group? We hypothesized that it did.

\section{METHODS}

\section{Context}

We conducted this study over three academic years $(2013,2014$, and 2015$)$ at Western University, a relatively large, research-intensive Canadian medical/doctoral institution. The specific academic setting was a course in the fall term followed by a companion course in the winter term in first-year evolutionary biology. The same cohort took both courses in a given academic year. These courses are part of a Bachelor of Medical Sciences program in which the required secondary school admission average was among the highest in the country relative to comparable programs. Most students in these courses identified primary healthcare as their main career goal. Average enrollment over the three years of the study was 1250 students, with roughly $60 \%$ identifying as female. Each week of the courses consisted of two 50-minute face-to-face lectures in an 800-seat lecture theatre, as well as one 180-minute laboratory session with a maximum of 40 students. The three faculty partners who instructed the courses, two male and one female, held weekly drop-in office hours for two hours each. A comprehensive course website, maintained on the university learning management system (LMS), provided access to announcements, course policies, lecture slides, etextbook readings, archived lecture recordings, assignments, and several discussion forums moderated by instructors. One such discussion forum permitted students' posts to appear anonymous to peers but still identifiable to instructors.

\section{Facebook group moderation}

The Biology Mentor Program (BMP) was founded in 2014 when a small group of senior undergraduate biology students approached the course instructor (Tom, also the corresponding author) to discuss how they might offer discipline-specific support to first-year biology students. The BMP was then co-designed as an informal, emergent students-as-partners project.

Our design team was aware that unofficial Facebook groups for our courses had often been created by individual students in the past. We thought that creation of more official, monitored, and moderated Facebook groups would improve the student experience. To get the program initiated, the course instructor recruited a cohort of 12 20 discipline-specific academic mentors and trained them to support a diverse student body in online environments. Mentors were near-peers in that they had taken the course within the previous two years. Although the BMP did eventually offer face-to- 
face workshops, the main initial responsibility of the BMP mentors was to work collaboratively with both instructors and students to create, populate, and moderate the interactions of an intentional learning community in a course Facebook group. No members of the instructional or administrative staff were included in the Facebook group.

Mentors were introduced to the class in the first lecture. They showcased the Facebook group as an optional, student-facilitated educational resource and invited students to join immediately. Mentor-moderators then encouraged online participation, posted course-related tips and recommendations, and modelled norms for group communication. They monitored posts and related comments for content inaccuracies, incivility, and academic dishonesty. Mentors alerted instructors to any significant problems with understanding that surfaced in the group. Such issues were then addressed in lecture with direct reference to the Facebook group. In a reciprocal way, instructors alerted mentors to any important revisions of lecture material or other course announcements. Mentors thus acted as trustworthy, arms-length liaisons between the class and the instructors.

A small group of these mentors, in collaboration with faculty partners, conducted all aspects of the program evaluation research that this article describes, from initial design to ethics approval to analysis to preparation of this manuscript.

\section{Data collection and analysis}

We studied Facebook groups from three academic years. The Facebook group for the 2013 cohort was created by an unidentified student and unmoderated. Facebook groups for the two subsequent cohorts, for academic years 2014 and 2015, were created and moderated by the BMP as described above. We retrieved all posts and comments from all three groups using the Grytics software from Grytics.com. The total numbers of combined posts and comments to discussion forums on the course LMS were reported by built-in system analytics.

Students were given the option of opting out of this study through email contact with the BMP research team. All Facebook posts from students who did not choose to opt out were numbered, and a random number generator was used to select which posts, and their associated comments, would be analyzed. In total, 928, 922, and 938 Facebook posts and comments were randomly selected for analysis from the 2013, 2014, and 2015 cohorts, respectively. The quality of posts and comments was assessed on a scale from -1 to 3 according to the rubric outlined in Table 1. Two raters from BMP independently scored the same 83 randomly selected posts with their 357 associated comments. Because strong agreement between raters was observed $(K=0.74)$, all subsequent posts and comments were analyzed by one evaluator or the other (McHugh, 2012).

We performed Student's t-tests to determine whether the scores of the posts and comments from the moderated groups were significantly different from that of the unmoderated group. 
Table 1: Criteria corresponding to the quality score of posts and comments.

\begin{tabular}{|c|c|}
\hline $\begin{array}{l}\text { Quality } \\
\text { Score }\end{array}$ & Criteria \\
\hline-1 & $\begin{array}{l}\text { Incivil (profanities, rudeness, insults to professors or peers, } \\
\text { etc.) } \\
\text { Prohibited quiz questions and/or answers (the entire thread } \\
\text { pertaining to this was deleted) }\end{array}$ \\
\hline 0 & $\begin{array}{l}\text { Irrelevant (“memes", pictures for entertainment, etc.) } \\
\text { Neutral (thank you, I don't get this, etc.) } \\
\text { Administrative (messages from professor about exams, } \\
\text { BMP workshop schedule, etc.) }\end{array}$ \\
\hline 1 & $\begin{array}{l}\text { Repeating material in the same thread } \\
\text { One-word answers (A, Yes, No, etc.) } \\
\text {. } \quad \text { Paraphrasing for clarification purposes } \\
\text { - } \quad \text { Asking for a response (e.g., "help me") }\end{array}$ \\
\hline 2 & $\begin{array}{l}\text { Initiating or extending a discussion } \\
\text { Attempting to answer questions posed. Can be scored a } 3 \text { if } \\
\text { additional criteria are met } \\
\text { Offering psychological support }\end{array}$ \\
\hline 3 & $\begin{array}{l}\text { If answering a question: } \\
. \quad \text { Answers question thoroughly (longer than } 3 \text { sentences) } \\
. \quad \text { AND/OR goes beyond course learning outcomes } \\
\text { AND/OR integrates multiple concepts } \\
\text { If asking a question: } \\
\text { Demonstrates critical thinking by integrating multiple } \\
\text { concepts } \\
\text { AND/OR goes beyond course learning outcomes }\end{array}$ \\
\hline
\end{tabular}

\section{RESULTS}

Figure 1 shows that, although the instructors, course content, and overall course structure remained essentially the same over the three academic years we examined, Facebook activity increased each year. Conversely, overall participation on the LMS course discussion forums fell by nearly half over the same period. In all years, the number of posts to Facebook per 100 students was at least tenfold higher than that on the respective LMS discussion boards. 
Figure 1: Number of posts and comments per 100 students, retrieved from the unmoderated 2013 Facebook group, the moderated 2014 and 2015 Facebook groups, and the LMS discussion boards

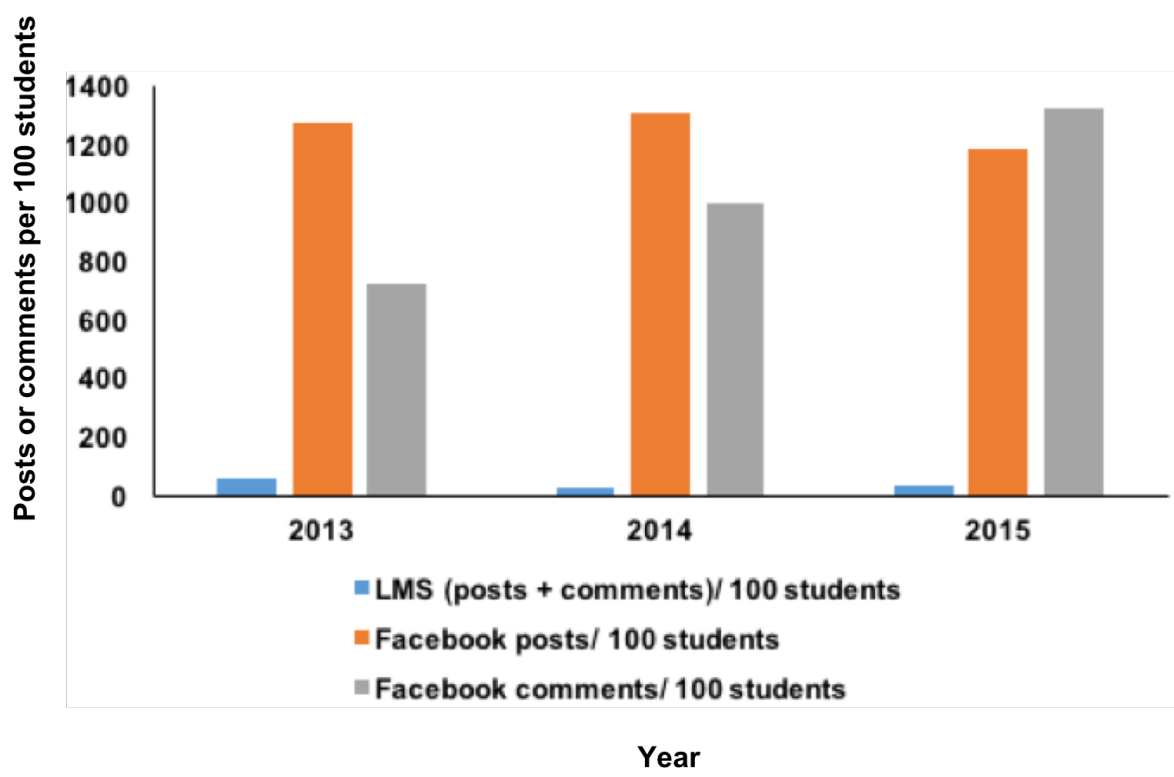

The quality of posts in the $\mathbf{2 0 1 5}$ moderated Facebook group was higher relative to the unmoderated group (see Figure 2). Moreover, the quality of comments was higher in both 2014 and 2015 moderated groups relative to the unmoderated group. All of these increases were statistically significant.

Figure 2: Post (a) and comment (b) quality from unmoderated 2013 Facebook group and moderated 2014 and 2015 Facebook groups. Means marked with the same letter are not significantly different. Posts: 2013 vs $2014, t(407)=-1.18, p=0.239 ; 2013$ vs 2015, $\mathrm{t}(380)=-3.37, \mathrm{p}=0.001)$. Comments: 2013 vs 2014, $\mathrm{t}(1933)=-5.39, \mathrm{p}<0.001$; 2013 vs 2015, $\mathrm{t}(1971)=-8.39, \mathrm{p}<0.001)$.

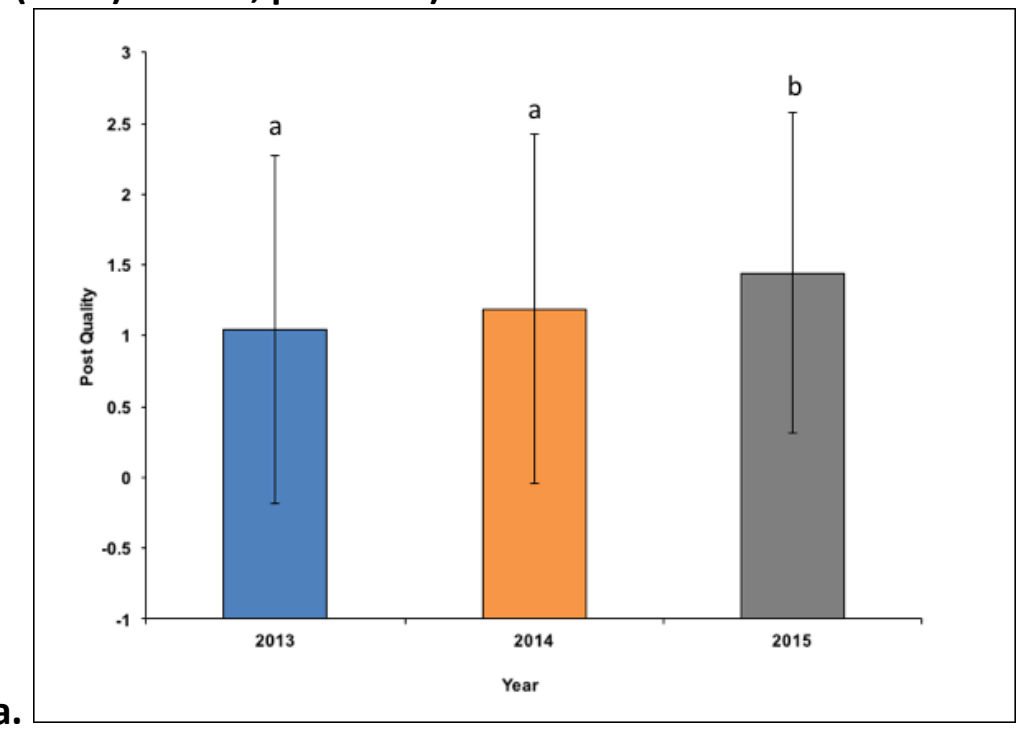




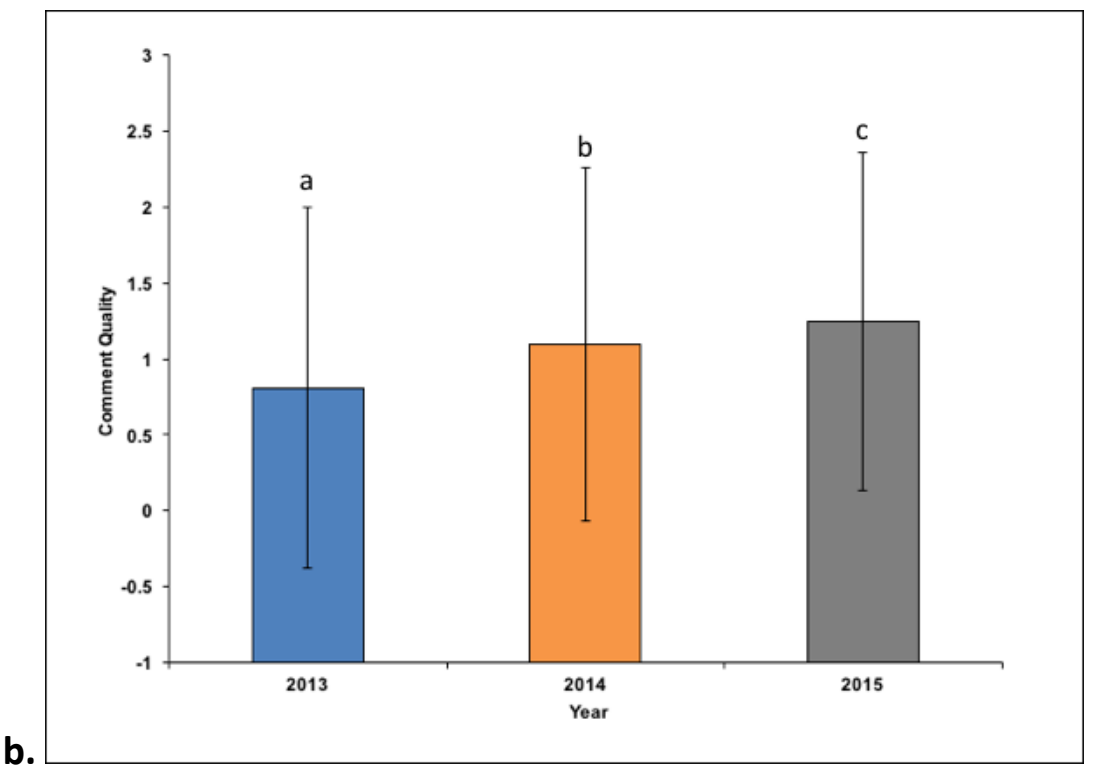

Figure 3 shows that moderated groups experienced an increased proportion of posts and comments that were directed at peer-helping and critical thinking (levels 2 and 3).

Figure 3: Distribution of rubric ratings for posts and comments from unmoderated (2013) vs. moderated (2014 and 2015) Facebook groups.

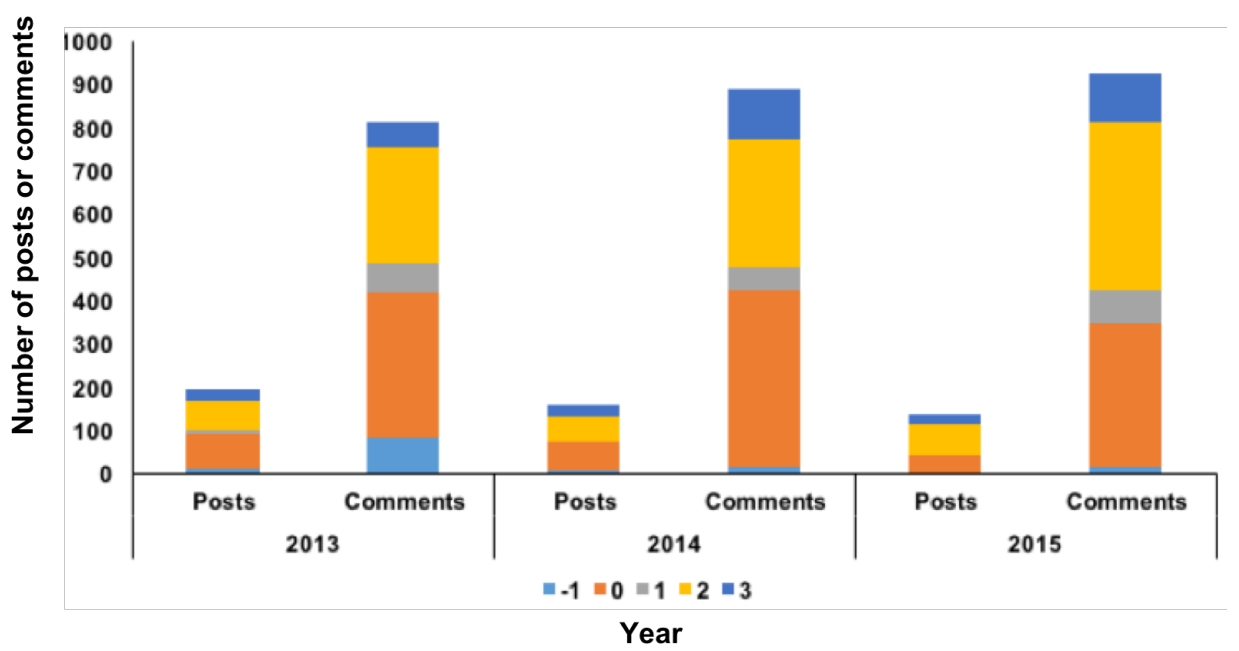

\section{DISCUSSION}

Previous studies have examined the relationship between course instructors' involvement in Facebook groups and students' learning (DiVall \& Kirwin, 2012; Schroeder \& Greenbowe, 2009). Our study was unique for two reasons. First, the moderation in our study was performed by near-peer student mentors, as opposed to course instructors or teaching assistants. Second, while the aforementioned studies did not compare the quality of the posts with and without moderation, we employed a rubric to assess the effect of moderation on the quality of students' interaction. 
Our results demonstrate a clear trend of increasing quantity and quality of activity from unmoderated to moderated Facebook groups. These data support our hypothesis that our near-peer Biology Mentorship Program promotes higher quality student interaction in a course-related Facebook group.

The increasing trend in the average number of posts and comments per student from unmoderated to moderated Facebook groups likely has several underlying drivers. Perhaps most importantly, near-peer moderators actively encouraged students to enroll in the group and share their thoughts. The initial invitation to join the group came live from mentors during the first class, clearly demonstrating that the program was sanctioned by instructors who were working in collaboration with mentors to improve the student experience.

Peer mentoring has been shown to discourage online harassment (Slonje, Smith, \& Frisén, 2013). Near-peer moderated groups may well have shown higher participation because of the safer space for discussion created through modelling of supportive online interaction, as well as active suppression of harassment and incivility. Furthermore, if the mentors were uncertain about an answer to a question, they consulted the faculty partner and then shared the answer with the students. This way, students uncomfortable with directly communicating with the professors could instead ask questions in a less intimidating environment, while still feeling confident that they would receive reliable answers.

The improvement in quality of online interaction in moderated groups likely has several contributing factors. The use of role models, defined by Côté and Leclère as "individuals admired for their ways of being and acting as professionals" (2000, p.718), has been described as a powerful teaching strategy (Cruess, Cruess, \& Steiner, 2008). The mentors in the Facebook group were trained to participate in a professional and helpful manner, setting an example of such behaviours to first year students. As such, it is possible that first-year students strove to model their posts and behaviours on that of the upper-year mentors, contributing to the higher quality discussions taking place in the moderated groups. The mentors also generally promoted academic integrity among the class and specifically prevented any inappropriate dissemination of assessment answers, etc. within the group.

The increasing quality of posts and comments between the first and second years of the moderated trials may be attributed to refinements in the mentorship program. Drawing on their experiences with the first moderated group, the student and faculty partners recruited more mentors to assist with moderating the group in the second year. In addition, the program created a weekly schedule for the mentors to ensure that the group was always moderated, and that questions were not left unanswered or incorrectly answered. Mentors also began hosting weekly workshops and office hours in an effort to build face-to-face relationships with the students.

Similar to the study by Schroeder and Greenbowe (2009), our study involved a course that provided both a Facebook group and a discussion forum on the official course LMS. In our study, the biology mentors clearly explained to the students the differences between the discussions that should be posted on each platform. Having access to both platforms allowed those students who chose not to use Facebook to still get their questions answered and discuss the course content with their peers. Furthermore, the official course LMS allowed for direct communication between 
students and course instructors. Our study as well as Schroeder and Greenbowe's revealed much higher participation in the Facebook group relative to the official course LMS. The main reasons for this are likely familiarity, convenience, and efficiency (Schroeder \& Greenbowe, 2009).

We assume that most students in our study came to their postsecondary classes with Facebook already integrated into their daily lives. Based on the personal experiences of the student authors as modern undergraduates, many students typically access Facebook several times daily and have configured settings to automatically alert them to new posts. As a result, participation in the Facebook group can be a rather seamless extension of their personal use of this social media platform. Although the LMS provides direct access to instructors, it is much less familiar, much less engaging in design, much less conveniently integrated into students' online experience, and much more exposed to instructor scrutiny. Once students realize early in the term that there is relatively little traffic on the LMS, this may create a self-reinforcing system in which fewer and fewer students bother to monitor and post to the LMS, despite encouragement from instructors and the option to post anonymously to peers.

Our mentor-moderation model may present the "best of both worlds" approach to course Facebook groups. That is, mentor-moderated groups may foster increased student engagement by providing timely, civil, reliable support to students without the privacy or self-presentation concerns concomitant with direct oversight by their instructors.

In general, we appreciate that our project placed Facebook in a "grey area" of informal, extracurricular educational resources that, while recommended by instructors, are otherwise outside of the direct control of the institution. Student participation on Facebook was not officially regulated nor protected by our institutional policies related to data hosting and security, student codes of conduct, etc. Such concerns may have led some students to avoid the Facebook option.

If we move our focus off the Biology Mentorship Program per se and look instead at the experience of the faculty and student partners, we find additional benefits of this program in areas such as deepening content knowledge, enhancing transferable skills, and opening new avenues of research and practice. The following brief reflections from faculty and student authors underscore these points:

The teamwork and collaboration skills I developed from creating workshops and working on this research project have served me well in my responsibilities as a medical student. These are skills (admin, organizing interviews, selecting applicants) that aren't necessarily taught to students directly. (Kevin, sixth author)

Having learned the value of mentorship, I continued to both seek mentorship from senior students and provide mentorship support to junior students. (Mohammad, first author)

The task of mentoring students on topics that I had not engaged with in depth for some time required me to revisit my old notes and reinforce concepts that I may have otherwise forgotten. Working with BMP transformed the content of first-year biology 
from a prerequisite for graduation, to a foundational knowledge base upon which to pursue my further education. (Tara, fourth author)

Thanks to the inspiration I received from this work, I continued to participate in developing a medical education project and subsequently quantitatively assessing its effectiveness and participating at various research venues. (Mohammad, first author)

Participating in a students-as-partners project has immersed me in the behind-thescenes of research that are often overlooked. This experience has granted me skills in data organization, statistical analyses, manuscript preparation, and time management. I've carried these skills with me into my Masters, making my transition from undergrad to Masters a smooth one! (Michelle, second author)

The BMP was a kind of gateway project for me as a faculty partner. The ease and success of working with enthusiastic and capable students in BMP was one of the motivators for me to create infrastructure supporting diverse students-as-partners projects across the Faculty of Science. (Tom, last author)

In summary, a students-as-partners near-peer mentor program was associated with increased quantity and quality of student course discussion in instructorsanctioned, moderated Facebook groups relative to unofficial, unmoderated groups, as well as a variety of benefits to the student mentors and faculty partner. We expect that students in other large courses would benefit from comparably supportive discussions in moderated course-specific Facebook groups. Future studies are needed to assess the role of peer moderation in other disciplines or course structures. Furthermore, the relationship between students' grades and their activity in the Facebook group could be investigated. As suggested by Legaree (2015), perhaps mentor-moderation influences students' use of this particular social media technology toward ways that improve their academic performance.

This research was carried out under Project ID 107655 as approved by the Non-Medical Research Ethics Board of Western University.

\section{NOTE ON CONTRIBUTORS}

Kevin Chien has since gone on to become a medical student at the University of Ottawa where he continues to be involved in medical education projects.

Mohammad Jay has since gone on to become a medical student at the University of Ottawa where he continues to offer, and receive, academic mentoring.

Khalid Hossein has since gone on to become a dental student at McGill University where he finds passion at the intersection of health care, research and education. 
Michelle Lim has since gone on to become a Masters student in Microbiology and Immunology at Western University where she was particularly instrumental in moving this manuscript to publication.

Syed Reza Naqvi has since gone on to become a medical student at Western University where he sees the value of student/faculty collaboration in education.

Tara White has since gone on to become a Masters student in Global Health at Vrije Universiteit in Amsterdam, where she conducts quantitative and qualitative research.

Tom Haffie is a faculty member, 3M National Teaching Fellow and a Teaching Fellow for Science at Western University, supporting faculty-wide students-as-partners programming.

\section{REFERENCES}

Al-Bahrani, A., \& Patel, D. (2015). Incorporating Twitter, Instagram, and Facebook in economics classrooms. The Journal of Economic Education, 46(1), 56-67. https://doi.org/10.1080/00220485.2014.978922

Alhabash, S, \& Ma, M. (2017). A tale of four platforms: Motivations and uses of Facebook, Twitter, Instagram, and Snapchat among college students? Social Media + Society, 113. https://doi.org/10.1177/2056305117691544

Bovill, C., Cook-Sather, A., Felten, P., Millard, L., \& Moore-Cherry, N. (2016). Addressing potential challenges in co-creating learning and teaching: Overcoming resistance, navigating institutional norms and ensuring inclusivity in student-staff partnerships. Higher Education, 71(2), 196-208. https://doi.org/10.1007/s10734-015-9896-4

Côté, L., \& Leclère, H. (2000). How clinical teachers perceive the doctor-patient relationship and themselves as role models. Academic Medicine, 75(11), 1117-1124. https://doi.org/10.1097/00001888-200011000-00020

Chugh, R., \& Ruhi, O. (2018). Social media in higher education: A literature review of Facebook. Education and Information Technologies, 23(2), 605-616. https://doi.org/10.1007/s10639-017-9621-2

Cruess, S. R., Cruess, R. L., \& Steinert, Y. (2008). Teaching Rounds: Role modelling-Making the most of a powerful teaching strategy. British Medical Journal, 336(7646), 718-721. https://doi.org/10.1136/bmj.39503.757847.BE

DeSchryver, M., Mishra, P., Koehleer, M. \& Francis, A. (2009). Moodle vs. Facebook: Does using Facebook for Discussions in an Online Course Enhance Perceived Social Presence and Student Interaction? In I. Gibson, R. Weber, K. McFerrin, R. Carlsen, \& D. Willis (Eds.), Proceedings of SITE 2009--Society for Information Technology \& Teacher Education International Conference (pp. 329-336). Charleston, SC, USA: Association for the Advancement of Computing in Education (AACE). https://www.learntechlib.org/primary/p/30612/

DiVall, M., \& Kirwin J. (2012). Using Facebook to facilitate discussion between students and faculty members. American Journal of Pharmaceutical Education 76(2), 1-5. https://doi.org/10.5688/ajpe76232

Freyn, A. (2017). Experimenting with Snapchat in a university EFL classroom. Journal of Education and Practice, 8(10), 35-37. https://files.eric.ed.gov/fulltext/EJ1139728.pdf 
Greenwood, S., Perrin, A., \& Duggan, M. (2016). Social media update 2016. Retrieved from Pew Research Center Internet \& Technology website: http://www.pewinternet.org/2016/11/11/social-media-update-2016/

Healy, M., Flint, A., \& Harrington, K. (2014). Engagement through partnership: Students as partners in learning and teaching in higher education. York, UK: Higher Education Academy. https://www.heacademy.ac.uk/system/files/resources/engagement through partner ship.pdf

Irwin, C., Ball, L., \& Desbrow, B. (2012). Students' perceptions of using Facebook as an interactive learning resource at university. Australasian Journal of Educational Technology, 28(7), 1221-1232. https://pdfs.semanticscholar.org/9df3/bc2be722869cd7de3da8805212fb6867f6e0.pd f

Legaree, B. A. (2015). Considering the changing face of social media in higher education. FEMS Microbiology Letters, 362(16), 301-303. https://doi.org/10.1093/femsle/fnv128

Manca, S. \& Ranieri, M. (2015). "Yes for sharing, no for teaching!": Social media in academic practices. Internet and Higher Education, 29, 63-74. https://doi.org/10.1016/j.iheduc.2015.12.004

Manca, S. \& Ranieri, M. (2016). Facebook and the others. Potentials and obstacles of social media for teaching in higher education. Computers \& Education, 95, 216-230. https://doi.org/10.1016/i.compedu.2016.01.012

Matthews, K. E. (2017). Five propositions for genuine students as partners practice. International Journal for Students as Partners. 1(2), 1-9. https://doi.org/10.15173/ijsap.v1i2.3315

McCole, D., Everett, M., \& Rivera, J. (2014). Integrating Facebook into the college classroom: student perceptions and recommendations for faculty. NACTA Journal, 58(3), 244-249. https://www.jstor.org/stable/nactajournal.58.3.244?seq=1\#page scan tab contents

McHugh, M. L. (2012). Interrater reliability: The kappa statistic. Biochemia Medica, 22(3), 276-282. https://doi.org/10.11613/BM.2012.031

O'Shea, S., Bennett, S., \& Delahunty, J. (2017). Engaging "students as partners" in the design and development of a peer mentoring program. Student Success, 8(2), 113-116. https://doi.org/10.5204/ssj.v8i2.390

Rivers, J., Smith, A., Higgins, D., Mills, R., Maier, A., \& Howitt, S. (2017). Asking and answering questions: Partners, peer learning, and participation. International Journal for Students as Partners, 1(1), 1-10. https://doi.org/10.15173/ijsap.v1i1.3072

Schroeder, J., \& Greenbowe, T. (2009). The chemistry of Facebook: Using social networking to create an online community for the organic chemistry laboratory. Innovate: Journal of Online Education, 5(4). http://www.learntechlib.org/j/IJOE/v/5/n/4/

Slonje, R., Smith, P. K., \& Frisén, A. (2013). The nature of cyberbullying, and strategies for prevention. Computers in Human Behavior, 29(1), 26-32. doi: 10.1016/j.chb.2012.05.024

Soluk, L., \& Buddle, C. M. (2015). Tweets from the forest: Using Twitter to increase student engagement in an undergraduate field biology course. F1000Research, 4(82), 1-12. https://doi.org/10.12688/f1000research.6272.1 
Thompson, J. (2007). Is education 1.0 ready for web 2.0 students? Journal of Online Education, 3(4), Article 5. https://nsuworks.nova.edu/innovate/vol3/iss4/5

Vaughan, N., Clampitt, K., \& Park, N. (2016). To teach is to learn twice: The power of peer mentoring. Teaching \& Learning Inquiry, 4(2), 1-17. https://doi.org/10.20343/teachlearninqu.4.2.7

Wang, Q., Woo, H., Quek, C., Yang, Y., \& Liu, M. (2012). Using the Facebook group as a learning management system: An exploratory study. British Journal of Educational Technology, 43(3), 428-438. https://doi.org/10.1111/j.1467-8535.2011.01195.x

Wang, Y., Fang, W.-C., Han, J., \& Chen, N.-S. (2016). Exploring the affordances of WeChat for facilitating teaching, social and cognitive presence in semi-synchronous language exchange. Australasian Journal of Educational Technology, 32(4), 18-37. https://doi.org/10.14742/ajet.2640

Weller, S., Domarkaite, G.K., Lam, J., Lam, C., \& Metta, L.U. (2013) Student-faculty co-inquiry into student reading: recognising SoTL as pedagogic practice. International Journal for the Scholarship of Teaching and Learning, 7(2), Article 9.

https://doi.org/10.20429/ijsotl.2013.070209 